\title{
CLAIMING THE SELF
}

\author{
Scott Kouri
}

\begin{abstract}
The article applies a critical analysis to multiple conceptualizations of the self with the aim of deepening the theorizing of self in Child and Youth Care discourse. Postmodern and Jungian psychology perspectives are used to contrast and offer alternatives to the dominant definitions of self in scientific psychology. The possibility of uniting these two alternative approaches is explored in terms of CYC praxis, and in return, postmodern and Jungian psychologies are used to vitalize and expand the theorizing related to the most elusive and stretched concept in CYC, the self.
\end{abstract}

In the online classrooms of the University of Victoria's School of Child and Youth Care, I am challenged to integrate my self into the matrix of the program's discourses and curricula. In doing so, however, I am confronted by the realization that some of the narratives and theories related to what I call my self fall outside the discourse of the school. With the reassurance and hospitality of those in the field, I have decided to share my journey in the spirit of shared inquiry.

The current article applies a critical analysis to multiple conceptualizations of the self with the aim of deepening the theorizing of self in Child and Youth Care (hereafter CYC) discourse. Postmodern and Jungian psychology perspectives are used to contrast and offer alternatives to the discourse of self in scientific psychology. The possibility of uniting these two alternative approaches is explored in terms of CYC praxis, and in return, postmodern and Jungian psychologies are used to vitalize and expand the theorizing related to the most elusive and stretched concept in $\mathrm{CYC}$, the self.

\section{The Self in Child and Youth Care Praxis}

The self is a highly touted concept in CYC discourse. Garfat and Charles (2007) claim that "it would be an understatement to say that self is central to Child and Youth Care Practice" (p. 1). Self is the context of CYC work, a way of being, and the essence of the helping relationship. The Association for Child and Youth Care Practice (2002) maintains that the self is foundational to CYC but cautions that "to make effective use of self in practice one must first be aware of and able to articulate the nature of the self" (p. 23). The self, however, is not theoretically grounded in CYC literature. Personal accounts and perspectives of the self are valued while at the same time the word is used seamlessly across texts. There appears to be a tension in CYC between essentialist views of the self and those emerging from constructivist or relational positions (Fewster 2001; Garfat \& Charles, 2007; Ricks, 1989; White, 2007). Maintaining this tension in the reflexive searching for the self is what I consider the quintessence of CYC praxis. 
So who am I as a practitioner? Where does my knowledge come from? How is it used? These abiding self-oriented questions, rather than their contextually specific answers, propel CYC praxis. The inquiring attitude which transforms practice into praxis is set within the discourse of CYC which defines praxis as knowing, being, and doing in context, or, the integration of theory and practice manifested in the application of selfunderstanding (White, 2007). Contrasted to contemporary ideas of practice, praxis is a more risky, free, and value laden form of action (Smith, 1999). In part, this is due to the relationships the two concepts have to theory. Smith argues that the classical view of theory is rule-based and in a domineering position vis-à-vis practice, whereas White contends that in praxis, words, actions, discourses, and experience merge in a union of theory and action. Praxis calls for an embodied, contextual, and narratively informed approach to practice: a reflexive self in action.

As a novitiate practitioner in a relatively young field, I am constantly motivated to articulate what and how I know. This inquiring and responsible attitude is crucial because CYC praxis situates me in a critical and problematic relationship with the dominant discourses of my culture. Rejecting the majority view that the complexities of human service can be conceptualized and measured in standardized forms and delivered by a homogenous group of practitioners, CYC praxis uses a web metaphor to appreciate the "active, intersecting, embedded, shifting and asymmetrical qualities of everyday practice" (White, 2007, p. 241). Articulating my epistemological stance, therefore, is central in the development of a richer and more open view of practice, as well as important for the development of the field. It is my intention to dig deeper into (or construct from a postmodern perspective) the nature of the self and explore various trends in self discourse.

I begin with a poststructural analysis of the deficit discourse in scientific psychology and lead into Jungian psychology as a promising perspective for defining the self in CYC. I believe that integrating postmodernism and Jungian psychology into a personal framework for practice is tantamount to the mixing metaphors, shifting narratives, and striving for meaning that constitutes scholarly praxis (Jones, 2003b).

\section{Discourse, a Brief Introduction}

The leap from language to discourse is an attempt to critically situate knowledge in relation to history, politics, and power (Law \& Madigan, 1998). For Foucault (1979), language is a binding social force which constitutes the world for the language user and maintains power positions within society. Language systems, such as psychology, psychiatry, and sociology, operate as discursive regimes that privilege normative systems of thought and action. As these discursive practices are elaborated and disseminated socially, their power is extended (Gergen, 2007).

Law and Madigan (1998) argue that a modernist interpretation of language treats phonetic utterances as reflecting the reality which they represent. Along with this relationship between words and reality comes the "expert" who is knowledgeable and controls the language forms. Contrary to this view is a poststructural analysis of discourse 
that emphasizes the specific actions that relate to institutionalized ways of talking. Discourse situates all claims to knowledge in relation to institutionalized rhetorical frames. Foucault (1980) argues that truth is produced by restraint and linked in a circular system of power relations. Therefore, no essential truths, realities, or structures exist; there is only discourse and relationships to and within it. A culture creates psychological realities through the interpretation of specific discourses while also re-enacting or recreating those discourses (Madigan, 1998). Cultural knowledge claims are therefore internalized and reproduced in social interactions and truths become living discursive actions which are situated in interpersonal relationships rather than handed down from above. Alternative constructions of reality are therefore subjugated through the practices of speaking enacted at an interpersonal level.

In order to illustrate the above discussion, I would like to explore the advent of the diagnostic category of attention deficit disorder (ADD). Embedded in the discourse of Western psychiatry, the construct and meaning of ADD has become a dominant narrative or truth regarding the behaviour of a large number of children (Law, 1998). Narrative practitioners such as Ian Law and Stephen Madigan (1998) argue that the discourse of pathology disseminated by the psychiatric community has the effect of rendering subjects passive and dependent. ADD is located within a decontextualized, debilitated, and deficient individual, while the ability to solve the problem resides with the medical community and pharmacology. The discourse of psychiatry, therefore, provides a frame of reference for interpreting experience, attributing meaning, and providing or prohibiting certain forms of action (Law, 1998). Labelling certain forms of behaviour has become a power base and control mechanism for service delivery with tremendous political and economic implications (Fewster, 2002).

Scientific psychology, as an institutionalized way of knowing, has emerged from history as the dominant voice regarding the self and its attributes and functioning. Social constructionist Kenneth Gergen (2007) emphasizes the political significance of the relationship between psychology and culture and concludes that all authority regarding issues of the human interior, including the individual subject's claims to self-knowledge, have been usurped. Cultural concern is now warranted as the discursive practices of scientific psychology transmit knowledge to the public to influence policy, silence alternative discourses, and sell merchandise.

\section{Scientific Psychology, Discourse of Deficits}

Gergen (2007) historically situates discourses of the self and relates them to their function within relationships and society. Beginning from the Greek precept to "know thyself" Gergen trails the metamorphic concept of the self to its modern formulations in scientific psychology. He shows that throughout history and into the present, definitions of the self are employed as stratagems for subcultures, such as psychology, which compete for discursive authority. A culture's dominant discourse, including its definition of self, can therefore be considered as made up of interconnected systems of language, none of which can be regarded as separate or unique. From this seemingly unitary position, a discourse functions to create a normative framework which mediates social 
relationships and delineates the matrix of activity, while sub-discourses compete and produce incompatible versions of reality (Law \& Madigan, 1998). Within this dynamic interplay of our culture's discourse, psychological science has achieved a colonial position in relation to other knowledge claims. As the language constructs of scientific psychology now guide the living traditions of society, they work to limit the influence of diverse traditions and language systems. Power relations and discursive colonization in psychology includes control of academic literature, research resources, university positions, and insurance coverage. In terms of self-definition, the image of the deficient, defective, or problem-saturated person holds currency (Gergen, 2007).

The scientific paradigm has overshadowed other voices in 20th century psychology, with functionalism and structuralism leading the way in therapy contexts (Law \& Madigan, 1998). Structuralism argues that the mind and meaning systems of a client are latent and discoverable through an analysis of external behaviours. Functionalism contends that behaviours are a response to earlier causes and serve a purpose within a system. Both approaches rely on expert knowledge and language, as well as the administration of power to determine access, treatment, rules, resources, and information. As such, the medical model can be said to have colonized family therapy. The language of the deficient self now characterizes persons, problems, families, and relationships in terms of lack and inadequacy.

Our society is quickly losing alternative forms of interpretation, self-definition, and action. We are losing our terminologies and grassroots vernacular and metaphors for understanding our experience (Gergen, 2007). Take, for example, the loss of our spiritual or romantic frameworks: We are being prescribed drugs for apathy and depression where once a religious discourse of guilt prescribed spiritual consultation and a relationship with God; being hung up on a girl, having the blues, and loving sex are now translated into obsession, depression, and addiction. Gergen (2007) argues that the language of deficits is also a language for moral and political control. He claims that classifying morally and politically neutral experiences (such as sadness or lethargy) as mental illnesses contributes to a process of pathologizing behaviours which are not socially acceptable. More potently, Thomas Szasz (2007) set out in the 1960s to show that mental illness was simply a label for socially disapproved behaviour. For 50 years he has advocated for gay rights in the face of a discourse that pathologized, diagnosed, and proposed cures for homosexuality.

Poststructural analysis contextualizes the use of language historically, politically, and in terms of power. Foucault (1980) describes discourse in terms of what can be thought and said, by whom, and with what authority. Discursive practices therefore establish, reflect, and construct prevailing power relationships inside and outside of therapy. While representing all institutionalized ways of talking, discourse also expresses what has not and cannot be said. At the same time, discourses themselves are established, reflected, and constructed by social dynamics and individual selves. It is this dialogical process which complicates the static notion of self with which I began this exploration. 
The historic trend of psychology to provide a vocabulary for the public to understand themselves in relation to institutions has achieved a level of ubiquity and social persuasion (Gergen, 2007). As psychological discourse becomes prevalent and available for the construction of everyday experience, symptoms serve as cultural models with which individuals can identify. Meaning-making is generally situated in relation to dominant discourse which discounts or pathologizes unique and individual accounts of reality (Madigan, 1998). Scientific psychology has successfully provided deficit terms for interpreting events and social relationships. Not only are terms such as depression, schizophrenia, dysfunctional family, lack of intimacy, communication problem, and personality disorders based on deficit language, they position the experience in a dependent relationship to help and change (Law \& Madigan, 1998). The practice of attributing undesirable behaviour to deficiencies of self is now a dangerously widespread practice. Socially acceptable behaviours are treated as psychological norms and variant behaviours are labelled undesirable and tied to mental illness (Szasz, 2007). Not only does the discourse of deficiency delimit conceptions of self, it acts as a means of moral and political control. Biased categorization of behaviours, thought processes, and emotions are used by individuals and families to make sense of their experience to the disqualification of personal or local knowledges. Nikolas Rose (2007) states:

As lay systems of meaning have become bound up with medical thought, medical languages, no matter how technical, have become infused with cultural meanings. Medicine thus makes us what we are by reshaping the relations of meaning through which we experience our worlds. (p. 701)

\section{Alternative Views}

Christopher Hauke, in his book Jung and the Postmodern (2000), argues that not only does the existence of a conceptual and social system, which includes expert knowledge and authority, exert pressure on individuals, but it also decides who the clients are in terms of their deviant rationalities, discourses, and language games. Hauke parallels the marginalization of alternative rationalities to the disenfranchisement of the unemployed and remarks that "in a culture where material consumption is viewed as highly rational behaviour, 'insanity' and poverty often go hand-in-hand" (p. 265). A pluralistic and postmodern alternative to the disempowerment of minority rationalities is proposed in a reading of Jung which positions "abnormal psychology as integral to the individual soul, to our culture and to the world" (p. 280). Furthermore, and in concert with the social constructionist outlook proposed by Gergen (2007), an overblown focus on the psychotic individual fails to appreciate the cultural function of psychosis and its embedding in cultural contexts.

In an attempt to connect across difference with respect and compassion, Doane and Varcoe (2006), two nursing professors in British Columbia, propose viewing families, nursing, and culture relationally. Rather than locating behaviours or problems in people or families, the authors suggest thinking "of the hard spots as arising when particular families and particular nurses in particular situations experience differences between them" (p. 15). Locating these "hard spots" dialogically opens the door to 
opportunities and strengths within the family rather than problematizing the family from an expert position. The positing of this relational approach necessitates inquiring into the experience or concerns of the family as well as the practitioner's experience and concerns. Knowledge is viewed as embedded within personal belief systems as well as situated within a social context where Eurocentric values and attitudes dominate. In responsive relationships, difference becomes an opportunity to connect and learn more about the diversity of human experience.

Hailing from the fields of CYC and education, Dahlberg, Moss, and Pence (1999) critique the globalization of the Western individualistic paradigm from a postmodern perspective. The universalizing of developmental theory and Western pedagogy has had devastating effects on traditional cultures worldwide. The majority world, however, has not stood idly by but has infused into Western philosophy an "uncertainty about certainty" (p. 165), which draws attention to the relationship between knowledge and power. This is echoed in Hauke (2000) who uses reflexivity and a multicultural agenda to challenge and undermine the rational discourses within which his postmodern arguments get articulated. These recognitions of diversity promote the values of difference, subjectivity, and situated definitions of health, sanity, family, practice, and rationality. Dahlberg, Moss, and Pence (1999) conclude that although there is a worldwide movement to reconnect with cultural beliefs and practices, which are nonetheless interested in accessing resources and institutions from the dominant society, there is also a powerful trend to synthesize the modern and postmodern that situates useful knowledge relationally and is based on a spirit of inquiry.

\section{Constructivist Perspectives}

\section{If a tree falls in the woods and no one is around to hear it, does it make a sound?}

Although constructivism encompasses a vast family or grouping of theoretical perspectives, Vance Peavy ${ }^{1}$ contends that they are all useful antidotes for positivist approaches to methodology, epistemology, and human service. In general, therefore, constructivist perspectives are in line with a growing number of disciplines that are moving forward into a postmodern and postindustrial world. Raskin (2002) depicts the postmodern era as accentuating the creation, rather than discovery, of knowledge and identities. In this paradigm, knowledge, identity, and truth are socially negotiated, contextually situated, and more interpretational and interpersonal than essential.

Constructivists can be divided along the lines of their views concerning the existence of an external reality (Raskin, 2002). Epistemological constructivists argue that there is an external reality, but that humans can only have knowledge of that reality through their constructions of it. On the other hand, hermeneutical constructivists do not believe in the existence of an observer-independent reality. Social constructionism, considered by Raskin as a hermeneutical constructivism, avoids the notion of an isolated knower and generally differentiates itself from constructivism on that point. For social constructionists, individual psychic life is primarily relational, conversational, and embedded in social practices. The self for social constructionists is therefore fluid, 
fleeting, and without a stable essence; the self changes in relation to social circumstances and multiple selves can exist within an individual as they simultaneously respond to multiple contexts. Each version of the self is a construction and therapy is intended to help persons create various self-constructions (Raskin, 1999).

As described above, the social constructionist, Kenneth Gergen (2007), argues that dominant discourses of the self contribute to the institutions that hold power in this society and marginalize competing traditions. As an alternative, he proposes a critical psychology which promotes radical and alternative ways of inquiry. The dismantling of hegemony within psychology is viewed as an act of denunciation towards the widespread oppressions and injustice in modern society. In terms of the self, Gergen's critical perspective claims that all mental constructions are in principle without decidable referent and therefore discursively indeterminable through empirical study. Psychology is shown to be unable to infer or define the self outside of its location in discursive practices. Gergen's poststructural analysis of the scientific psychology text is convincing as he unmasks many of the sustaining metaphors within modern conceptualizations of the self.

Jones (2007), however, argues that when deconstruction is aimed at ideological unmasking, the critic forfeits critical distance and habitually interjects an alternative ideology. This trend is evident in Gergen who proposes a socially constructed view of the self after disputing the modernist paradigm. Jones, on the other hand, strives at a reconstruction of meaning for modernist texts, such as Jung, and attempts to translate these views of the self back into postmodern psychology.

\section{The Jungian Self}

It is interesting for me to think that as postmodern critiques are increasingly being levelled against discursive hegemony in culture, and especially psychology, the door is being opened to the one psychologist whose discounted voice resonates most clearly with postmodern and CYC agendas. This trend is further amplified by the plurality of voices on the post-Jungian stage, including those labouring to reconcile Jung's modernism with his postmodern trends (Jones, 2003a; Hauke, 2000). Although an account of the diverse threads in post-Jungian thought and their interweavings with the postmodern is not within the scope of this article, I will use some of Jung's classical ideas about the self as a jumping off point for my engagement with postmodernism and CYC praxis.

As early as the 1900s, in his doctoral dissertation and work at the Burgholzli psychiatric hospital, Jung used the concept of teleology, or the purposive, to help his clients find meaning and value in their experience. Jung did not pathologize, rather he searched for the goals towards which symptoms or psychological experience was moving the client. Teleology, as a basic point in Jung's epistemology, explores the purpose and aims of phenomenon as they relate to individual goals in development (Papadopoulos, 2006). Jung's teleology contested Aristotle's fallacy of final causes and posited instead an explanatory framework more comparable to a systems theory perspective (Jones, 2003b; McDowell, 2001). In contrast to developmental theories which posit that 
symptoms are the result of failed attempts at normative development, Jung (1928) proposes that symptoms are manifestations of an urge towards self-realization and the maturation of the unique personality. From Jung's epistemological point of view, "knowledge is in the very process of generating itself" and "involves the locating of oneself on the pathway along which teleology is unfolding as a lived experience" (Papadopoulos, 2006, pp. 30-31). Complete knowledge of symptoms and behaviours are therefore impossible as they are always related to future goals, purpose, and meaning. Jung conceived of these particular goals as a sense of purpose or the unfolding of the self.

In his earlier writings, Jung used the term individuality in place of the self. Later, he conceptualized the self as both the center and totality of the psyche, encompassing both conscious and unconscious elements (Colman, 2006). The self in Jungian psychology represents totality, self-realization, equilibrium, and the principle of orientation and meaning. Polly Young-Eisendrath and James Hall (1991) claim that in Jung's work the "self can refer to the notion of inherent subjective individuality, the idea of an abstract center or central ordering principle, and the account of a process developing over time" (p. 5). The self as a process of psychological development, rather than a structure, function, or content of the psyche, leads to an appreciation of the dynamics of the psyche as a whole and reflects a general shift in Jungian psychology (Main, 2008). Colman (2006) accentuates "the intimate link between the self, as the essence of individuality, and individuation as the process by which that individuality may be realized" (p. 153). The self as an ordering and centering of the process of individuation is, therefore, in pursuit of wholeness and meaning.

The application of the core Jungian concepts of self, individuation, and teleology depends on the view that the individual's psychological experience is real. The postulation of psychic reality contends that all experience is primarily psychic and that the mental states, emotions, thoughts, beliefs, and feelings of individuals are facts. Jung, although criticized by many as esoteric and mystical, is not exceedingly interested in the objective existence of gods, spirits, or UFOs; rather, he is interested in the psychological meaning these subjective experiences have for the individual. A Jungian perspective focuses on how an individual's psychic experience is moving them towards a more whole and meaningful existence. It is of interest for me to see the similarity between (a) the social constructionist's argument that narratives are reality directed and woven into the fabric of life rather than fictions imposed upon reality (Freeman, 1999, 2007), and (b) the definition of psychic reality in A Critical Dictionary of Jungian Analysis as the awareness that "one experiences life and its events in terms of narrative truth rather than historical truth" (Samuels, Shorter, \& Plaut, 1986, p. 117).

To summarize and prepare for what is ahead: Jung affirms the meaning and importance of subjective and contextualized psychological experiences and searches for their underlying purposive or teleological direction. These psychological meanings propel the self-structuring of the psyche and the processes of individuation. 


\section{The Whole Self in the Union of Opposites}

The title of this section is borrowed from Lucy Huskinson's (2004) study of the thought and personalities of Jung and Nietzsche. In her book, Huskinson not only elaborates how these two psychologists used the term self, but also compares each definition from the perspective of the other. Similarly, I believe a great deal of light can be shed on the current investigation by looking at social construction and critical theory from a Jungian perspective, and vice-versa. This interpretive task is seeking to bridge the two worlds through praxis.

On the one hand, Jung is "paradigmatic of the grand-theory era" (Jones, 2003a), while on the other, he esteems the importance of what he called "the personal equation" noting that every theory arises out of the personal psychology of the theorist thereby precluding claims to final truth (Hauke, 2000). Analytic psychology generally pertains to an intra-individual psyche that is projected outwards to create culture, myth, and language. Jung posits the direction of energy as moving from within the individual towards objects and imbuing them with significance and meaning. From this perspective, the postmodern trend can be seen as a psychological attending-to which is significant and meaningful for many individuals. It can also be considered as a compensatory position for the lack of meaning that individuals have found in modern culture. Using the postulates of psychic reality and the primacy of the psychological, an individual in analysis is encouraged to explore the meaning of postmodernism and its symbols.

Social constructivism, conversely, primarily pertains to the supra-individual power structures manifest in social discourses, which are internalized into people's private discourses (Jones, 2003a). What is taken to constitute selfhood (doing, saying, and feeling) could be shown to originate in language-enabled social processes. Language therefore is the connector between meaning, power, and knowledge. From this perspective, Jungian psychology, and psychology generally, is itself a cultural discourse. Our self is embedded in the cultural discourses of our day and therefore retains no essence or center of meaning.

\section{Claiming the Self}

"A clash of doctrines is not a disaster, it is an opportunity." Whitehead (1967)

It should be evident by this point that I consider local definitions of the self as valid, interesting, and full of meaning. In my understanding, this appreciation is supported by the multi-voiced character of CYC, Jungian psychology, and postmodernism. In this section, I will briefly survey common areas among postmodernism, CYC, and Jungian psychology that hold promise for me as an individual, scholar, and CYC practitioner. This work is an opening gambit for a fuller exploration of the incorporation of Jungian analysis in CYC contexts. 
CYC theory pulls from a variety of orientations in the definition of self. Garfat and Charles (2007) summarize that the self is the lens through which we perceive and interpret, while at the same time it is the sum of all our aspects and more. On the one hand, self is contextualized, situated in relationships and constructed within social discourse, while on the other hand, the self is the unique and essential or core of the personality. Jones (2003a) argues that tarrying to formulate a theoretical position between the modern and postmodern runs the risk of placing oneself in the crossfire between the two. Larner (2003), on the other hand, suggests an ethics of hospitality that invites all to engage in a constructive "both/and" dialogue in therapeutic discourses and approaches. He uses the term "paramodern" (p. 215) to place the modern and postmodern side by side, arguing that holding the tension between different perspectives opens the door to diversity of theory and practice.

The School of Child and Youth Care promotes divergent thinking on psychotherapeutic orientation and values the integration of multiple views in the creation of a personal framework for practice. Ricks ${ }^{2}$ argues that a theory guides thinking, allows us to be intentional, and helps organize ideas in order to communicate. The Jungian model has provided definitions and constructs that I use to create, communicate, and practice. It is interesting to balance the master-narrative critiques that Lyotard (1984) levelled against modernist theory building with the pluralistic point of view expressed in Jung's belief that every theory reflected its author. Furthermore, theory, in a CYC praxis framework, is a dynamic process that includes self and others in the creation of knowledge and the application of that knowledge in practice.

Gerry Fewster (2001), a leading self theorist in CYC, blends essentialism and social constructionist theory in his articulation of how a self develops. He primarily situates the self relationally, but contends that an essential or core aspect of himself reveals his divinity and place within the whole. He uses the language of postmodern science (chaos theory, quantum theory, and complexity principles) to hint at the potential of a self with limitless potential and connectedness. For Fewster, the core or authentic self finds expression and development in relationship with other authentic selves. When these relationships are unsupportive or unavailable, however, the core self is lost and a socially negotiated self becomes prominent. This socially constructed self is seen by Fewster as illusory or false and dependent on the expectations of others for motivation. This description of the self is an excellent example of how CYC practitioners and scholars must create their own definitions of self based on their experience, context, and beliefs. Fewster's (2001) conceptualization of the self is a helpful example of how modern and postmodern ideas need not be understood as contradictory, but can both inform the ways we make meaning of our selves in praxis. It is interesting to know that Fewster mentions at least two core Jungian ideas, the shadow and individuation, in his theory of himself.

In remarkable similarity to our praxis approach in CYC, Jung emphasized the personal characteristics and development of the analyst over her technical or medical expertise (Samuels, Shorter, \& Plaut, 1986). Jung is perhaps the first psychologist to acknowledge the emotional involvement of the analyst and require a training analysis for 
those wishing to practice. Moreover, Jung conceptualized analysis as a dialectical and relational process in which the analyst was as much "in" therapy as the client (Samuels, 2006). The involvement of the analyst at such a personal level has been taken by some analysts to include the woundedness of the healer and the therapeutic value of the client's ability to help the analyst (Sedgwick, 1994). Analysis accelerates the process of individuation through the co-creation of knowledge within an interactive and mutually validating relationship. Jung is shown here as a forerunner to therapeutic alliances, mutuality, and praxis.

In terms of methodology, Jungian, CYC, and social constructionist perspectives show concern for the "continuities and discontinuities of human life at the level of the person and personal meaning, rather than statistical regularities at the level of aggregates or reduction to performances in experimental procedures" (Jones, 2003a, p. 367). Following this belief, discursive analysis of the self is similar to Jungian theory in that it cannot be verified in a scientific sense. The postmodernism of Foucault suggests a valuing and recognition of "local" knowledges or alternative descriptions, which are extensively silenced through the disqualifying discourses of the majority (Madigan, 1998). Paralleling the recognition of individual narratives, Jung's thesis of the reality of the psychic experience elevates his clients "psychotic irrationality" to a level of meaning and coherence (Hauke, 2000). Fewster (2002) draws on personal and professional experience in a complete refutation of the diagnostic categories of the American Psychological Association's DSM-IV. The dedicated CYC practitioner takes up a seemingly postmodern analysis of the consensuality, objectification, and power related to standard categorizations of families and youth. Epistemologically, all three discourses value the contextual and co-constructed nature of knowledge. Methodologically, such attitudes manifest as participant action research, integrative approaches, intersectional analysis, and collaborative and qualitative inquiry. In practice they translate to a collaborative, relational, and strengths-based approach.

Strengths-based practice holds that a client is the expert about their life and as such should have an active part in assessments, goal setting, and the determination of goal achievement (Steven, 2007). It is my contention that the client-centered and relational approaches found in CYC are resonant with the Jungian principles of teleology and psychic reality. Teleology is a lens through which all experience and behaviour can be seen as oriented towards a purpose. These purposes are generally considered by Jungians as movements towards goals of individuation or the developmental process of the self (Colman, 2006). The concept of psychic reality conjointly privileges a client's construction of experience over an objective or expert explanation. In both cases, the meaning of behaviour is contextualized within an individual's psychological system and informs a client-centered strengths-based approach.

When theorizing about the self, the late social constructivist and professor emeritus at the University of Victoria, Vance Peavy ${ }^{1}$, employs a spatial metaphor as an alternative for the traditional view of the self. The author emphasizes the individual's meaning-making in relationships rather than in the context of an ecological system. He suggests digging deep into the layers of semantic and social space for meaning. This view 
reflects Jung's hermeneutic approach to an individual's subjective psychology and Jennifer White's (2007) constructivist and hermeneutic approach to CYC praxis. While Peavy puts forward a multiple-self view that is at odds with Jung's more unitary conceptualization, I do, however, find that there is a resonance with Jung's complex theory, which "rests on a refutation of monolithic ideas of personality" (Samuels, Shorter, \& Plaut, 1986, p. 33). The considerable difference lies in Jung's view of the autonomy of these entities and Peavy's ideas of the self being relational and narrated. Colman (2006), however, argues that there is not a great contrast between constructivist and essentialist viewpoints of the self since most Jungians would agree that the self depends on a particular context for its realization.

In the practical realm of youth work and counselling in general, Peavy argues for practitioners to resist the idea that they must be objective towards other people. Rather, he proposes that practitioners become reflexive towards themselves in order to deconstruct the assumptions and bias which underlie their practice. As mentioned above, Jung emphasized the importance of a training analysis for practitioners to become aware of their own self before engaging with others. Furthermore, the Jungian principles of psychic reality resonates with Sibylle Artz's (2000) suggestion that listening carefully to how clients see the world and themselves supports an attitude of inquiry rather than one plagued by assumptions. Through critical reflection on social conditions that influence subjectivity, practitioners are able "to accept partiality, multiplicity, randomness, incoherence, and uncertainty" (Artz, 2000, p. 54). Further, Hoskins (2003) discusses how listening is the essential step to knowing anything about an individual's relationship to culture, without which, action remains unproductive. Both Hoskins and Artz agree that by keeping the complexity of experience in the foreground, practice remains effectual and grounded in relationships. Aston (2008) proposes a feminist poststructural model when dealing with information and discourse. She argues that by analyzing personal experiences, practitioners can help individuals choose what discourses to integrate into everyday practices. How dialogue occurs between client and practitioner becomes even more important when there is intent to challenge oppressive myths and stereotypes. Applying this analysis brings the client's subjectivity and agency to bear on some of the dominant discourses with which they engage. A feminist poststructural approach locates individuals as interactive in relation to discourse, with the ability to challenge and possibly change their own circumstances and the circumstances of others. This approach illustrates the possibility of working dialogically with the self to influence discourse on both a personal and social level.

Ricks and Bellefeuille (2003) argue that through an unceasing inquisitive stance and a suspension of knowing, ethics therefore become a lived experience situated and created in the context of the relationship. Moreover, Garfat and Ricks (1995) position the self as the driving force behind understanding, processing, and acting in the resolution of ethical dilemmas. Like Jung, the authors support a view of the self as the mediator of experience and the basis for acting ethically in relationships. Ricks (1989) describes the self in terms of configurations within temporal dimension that manifest as thoughts, feelings, and acts. These positions are postures of the self and are "bottom line statements of one's being or the essence of who one is" (p. 39). Furthermore, Ricks contends that 
"these constructions of one's reality... are constructed from one's reality and they serve one by maintaining that reality" (p. 39). Again in Ricks we see the interweaving of an essentialist and constructivist view of the self.

The tension in CYC between the modern and postmodern opens the door for individual practitioners to apply their self in the development of theory and action. In this paper I have integrated the essentialism of Jung with a constructivist attitude to highlight avenues for future research in CYC theory. Bringing these threads together, Anglin ${ }^{3}$ conceives of the ethical practitioner as one who works with theories that lend themselves to being integrated into their authentic, genuine personality. Taking these tensions out into the field of CYC, praxis emerges from the web of theory, action, and self.

\section{Coming Full Circle}

"We cannot wait for perfect theories nor do we want them. We're in process. Theory is as alive as ethics, we breath life into it, we don't want to give birth to dead theory."

(Reynolds, 2010)

In the spirit of postmodernism, CYC praxis, and Jungian psychology, this paper has submitted a personal exploration and account of self in reflexive action. I have maintained multiple ways of knowing which is considered as a central strength in CYC praxis (White, 2007) and have used the Jungian interplay of opposites to be the very energy fuelling my work. This article is a symbol of my individuating self in praxis and articulates a local narrative within the discourse of Child and Youth Care. 


\section{References}

Artz, S. (2000). Considering adolescent girls' use of violence: A researcher's reflections on her inquiry. The B.C. Counsellor, Journal of the British Columbia School Counsellors' Association, 22(1), 45-54.

Association for Child and Youth Care Practice. (2002). North American certification project (NACP). Competencies for child and youth work practitioners. Journal of Child \& Youth Care Work, 17, 16-29.

Aston, M. (2008). Public health nurses as social mediators navigating discourses with new mothers. Nursing Inquiry, 15(4), 280-288.

Colman, W. (2006). The self. In R. Papadopoulos (Ed.), The handbook of Jungian psychology (pp. 153-174). New York: Routledge.

Dahlberg, G., Moss, P., \& Pence, A. (1999). Beyond quality in early childhood education and care: Postmodern perspectives. Philadelphia: Falmer Press.

Doane, G., \& Varcoe, C. (2006). The hard spots in family nursing: Connecting across difference and diversity. Journal of Family Nursing, 12(1), 7-21.

Fewster, G. (2001). Selected writings. Turning myself inside out: My theory of me. Journal of Child and Youth Care, 15(4), 89-108.

Fewster, G. (2002). The DSM IV you, but not IV me. Child \& Youth Care Forum, 31(6), 365-380.

Foucault, M. (1979). Discipline and punish: The birth of the prison. New York: Pantheon.

Foucault, M. (1980). Power/knowledge: Selected interviews and other writings, 19721977. New York: Pantheon Books.

Freeman, M. (1999). Culture, narrative, and the poetic construction of selfhood. Journal of Constructivist Psychology, 12(2), 99-116.

doi: $10.1080 / 107205399266136$

Freeman, M. (2007). Psychoanalysis, narrative psychology, and the meaning of "Science". Psychoanalytic Inquiry, 27(5), 583-601. doi: $10.1080 / 07351690701468124$

Garfat, T., \& Charles, G. (2007). How am I who I am? Self in child and youth care practice. Relational Child \& Youth Care Practice, 20(3), 6-16. 
Garfat, T., \& Ricks, F. (1995). Self-driven ethical decision-making: A model for child and youth care. Child \& Youth Care Forum, 26(4), 393-404.

Gergen, K. (2007). The self: Colonization in psychology and society. In M. Ash \& T. Sturm (Eds.), Psychology's territories: Historical and contemporary perspectives from different disciplines (pp. 149-168). New York: Routledge.

Hauke, C. (2000). Jung and the postmodern: The interpretation of realities. Philadelphia: Brunner-Routledge.

Hoskins, M. L. (2003). What unites us, what divides us? A multicultural agenda within child and youth care. Child \& Youth Care Forum, 32(6), 319-336.

Huskinson, L. (2004). Nietzsche and Jung: The whole self in the union of opposites. New York: Brunner-Routledge.

Jones, R. A. (2003a). Between the analytical and the critical: Implications for theorizing the self. Journal of Analytical Psychology, 48(3), 355-370. doi: 10.1111/1465-5922.t01-2-00005

Jones, R. A. (2003b). Mixed metaphors and narrative shifts: Archetypes. Theory \& Psychology, 13(5), 651-672.

Jones, R. A. (2007). Jung, psychology, postmodernity. New York: Routledge.

Jung, C. G. (1928). The relations between the ego and the unconscious. In Sir H. Read, M. Fordham, \& G. Adler (Eds.), The collected works of C. G. Jung (Vol. 7). Princeton, NJ: Bollingen.

Larner, G. (2003). Integrating family therapy in child and adolescent mental health practice: An ethic of hospitality. Australian and New Zealand Journal of Family Therapy, 24(4), 211-219.

Law, I. (1998). Attention deficit disorder: Therapy with a shoddily built construct. In S. Madigan \& I. Law (Eds.), Praxis: Situating discourse, feminism \& politics in narrative therapies (pp. 109-140). Vancouver, BC: Cardigan Press.

Law, I., \& Madigan, S. (1998). Discourse not language: The shift from a modernist view of language to a post-structural analysis of discourse in family therapy. In S. Madigan \& I. Law (Eds.), Praxis: Situating discourse, feminism \& politics in narrative therapies (pp. 1-12). Vancouver, BC: Cardigan Press.

Lyotard, J.-F. (1984). The postmodern condition: A report on knowledge. Manchester: Manchester University Press. 
Madigan, S. (1998). Practice interpretations of Michel Foucault. In S. Madigan \& I. Law (Eds.), Praxis: Situating discourse, feminism \& politics in narrative therapies (pp. 13-34). Vancouver, BC: Cardigan Press.

Main, S. (2008). Childhood re-imagined: Images and narratives of development in analytic psychology. New York: Routledge.

McDowell, M. J. (2001). Principle of organization: A dynamic-systems view of the archetype-as-such. Journal of Analytical Psychology, 46(4), 637-654.

Papadopoulos, K. (2006). Jung's epistemology and methodology. In R. Papadopoulos (Ed.), The handbook of Jungian psychology (pp. 7-53). New York: Routledge.

Raskin, J. D. (1999). Metaphors and meaning: Constructing the creative psychotherapist. Journal of Constructivist Psychology, 12(4), 331-347.

Raskin, J. D. (2002). Constructivism in psychology: Personal construct psychology, radical constructivism, and social constructionism. In J. D. Raskin \& K. Bridges (Eds.), Studies in meaning: Exploring constructivist psychology (pp. 1-25). New York: Pace University Press.

Ricks, F. (1989). Self awareness model for training and application in child and youth care. Journal of Child and Youth Care, 4(1), 33-41.

Ricks, F., \& Bellefeuille, G. (2003). Knowing: The critical error of ethics in family work. In T. Garfat (Ed.), A child and youth care approach to working with families (pp. 117-130). Binghamton, NY: The Haworth Press, Inc.

Rose, N. (2007). Beyond medicalisation. Lancet, 369(9562), 700-702.

Reynolds, V. (Speaker). (2010). Social action and academia: Part 1 [Video file]. Retrieved from http://www.youtube.com/watch? $\mathrm{v}=$ ov1YKL8TBz0

Samuels, A. (2006). Transference/countertransference. In R. Papadopoulos (Ed.), The handbook of Jungian psychology (pp. 153-174). New York: Routledge.

Samuels, A., Shorter, B., \& Plaut, F. (1986). A critical dictionary of Jungian analysis. New York: Routledge.

Sedgwick, D. (1994). The wounded healer: Countertransference from a Jungian perspective. New York: Routledge.

Smith, M. (1999). Praxis: An introduction to the idea plus an annotated booklist. Retrieved March 3, 2009, from http://www.infed.org/biblio/b-praxis.htm 
Steven, E. G. (2007). Perspective analysis: McKnight's careless society and the strengthsbased approach to social work. Social Work, 52(3), 275-277.

Szasz, T. S. (2007). The medicalization of everyday life: Selected essays. Syracuse, NY: Syracuse University Press.

White, J. (2007). Knowing, doing and being in context: A praxis-oriented approach to child and youth care. Child \& Youth Care Forum, 36(5), 225-244. doi:10.1007/s10566-007-9043-1

Whitehead, A. N. (1967). Science and the modern world. New York: The Free Press.

Young-Eisendrath, P., \& Hall, J. (1991). Jung's self psychology: A constructivist perspective. New York: Guilford Press.

\section{Endnotes}

${ }^{1}$ Peavy, V. (Speaker). (n.d.). Applying constructivist theory in CYC 205: Applying change theory in child and youth care practice (Course content audio file). Victoria, BC: University of Victoria. Retrieved April 3, 2009, from http://owl.uvcs.uvic.ca/movies/cyc301/peavy.mp3

${ }^{2}$ Ricks, F. (Speaker). (n.d.). The significance of theory in CYC 205: Applying change theory in child and youth care practice (Course content audio file). Victoria, BC: University of Victoria. Retrieved October 20, 2008, from course electronic blackboard.

${ }^{3}$ Anglin, J. (Speaker). (n.d.). The humanistic approach in CYC 205: Applying change theory in child and youth care practice (Course content audio file). Victoria, BC: University of Victoria. Retrieved February 17, 2009, from course electronic blackboard.

Scott Kouri is an undergraduate student in the school of Child and Youth Care at UVic and a director of the C. G. Jung Society of Victoria. He has been working with the Fairfield Community Association's child and youth programs for five years. His shortterm goals include completing a Masters in CYC and developing a counselling practice that integrates postmodern and analytic psychology theory. 